\title{
Individual Factors as Determinants of Male Partner Involvement in Antenatal Care in Kiambu County, Kenya
}

\author{
Esfer K. Mbua (MScN, BScN, KRCHN) \\ Kiambu County Government - Health, Kenya
}

\begin{abstract}
Male partner involvement in maternal health is crucial in reducing maternal neonatal morbidity and mortality as well as a crucial component in the optimization of Maternal and Child Health services. Despite global efforts to improve male partner involvement, in Kenya this has remained low. This study explored individual factors that determine of male partner involvement in antenatal care in Kamenu Ward, Kiambu County. Specifically, the study looked into the effects of individual male partner factors such as the demographic factors and knowledge on male partner involvement in antenatal care. The study adopted a descriptive cross-sectional survey design which provided both quantitative and qualitative data. Self-administered questionnaire was used to collect data from 384 male partners aged 18 - 90 years who were residents of Kamenu Ward. Correlation results revealed that male partner's individual factors had significant positive relationship with their involvement in ANC. It was concluded that male partner factors such as knowledge of ANC, level of income, nature of employment, age, marital status, religion and level of education influences male partner involvement in ANC positively. The researcher recommends management of health facilities to ensure that male partners are encouraged to actively participate in their spouses ANC as this plays a vital role in improving the health of the mother and the baby.
\end{abstract}

Keywords: Male partner involvement, Antenatal care, Pregnancy, Maternal health

DOI: $10.7176 / \mathrm{JHMN} / 97-02$

Publication date: January $31^{\text {st }} 2022$

\section{Introduction}

\subsection{Background information}

Male partner involvement is referred as male partners actively participating in protecting, promoting the health and wellbeing of their spouses and children which is realized when male partners support decisions and activities that improve maternal health (Yargawa \& Bee, 2015). In this regard, it is currently being promoted and adopted globally, nationally and at sub-national level through policy and program planning as a promising strategy to improve MNH (Thomson, et al., 2015).

In addition, male partner involvement offers them an opportunity to participate in their spouses and child's care and provide physical and emotional support during and after pregnancy (Well, et al., 2015). Despite the efforts put in place to improve male partner involvement, this has remained low in Kenya. Therefore, this study explored the individual factors that determine male partner involvement in antenatal care in Kamenu Ward, Kiambu County. Male partners can positively influence $\mathrm{MCH}$ in a variety of ways, therefore, when informed can make sound decisions on behalf of the family for better health (Akinpelu \& Oluwaseyi, 2014).

They can encourage their pregnant spouses to attend ANC, accompany them, help prepare and save money for delivery, and arrange transportation to the birthing center, among other responsibilities (Sigh, et al., 2014). In addition, Thomson, et al. (2015) study revealed that there are many benefits associated with male partner involvement in $\mathrm{MNCH}$, including improved health outcomes for women, newborns and children, increased couple communication and improved relationships, reduced maternal workload and increased maternal nutrition and rest during pregnancy, increased value of girl child and health/wellbeing benefits for women.

\subsection{Individual Factors that Influence Male Partner Involvement in Antenatal Care}

This section presents literature information on age, level of education, occupation, marital status, and religion.

1.2.1 Age

In East New Britain, male partner involvement increased with age, older male partners supported their pregnant spouses financially (Holmes, et al., 2012). In Africa, Older male partners were found to be more likely to assist their partners in making a birth plan (Kakaire, et al., 2011). In Nigeria, proportion of male partners accompanying their pregnant spouses to ANC increased as age increased (Nkuoh, et al., 2010). Similarly, a study in sub-Saharan Africa found out that older male partners were more involved in ANC (Ditekemena, et al., 2012). According to Doe (2013) older men are likely to have a higher risk perception than younger men. In East Africa, a study in Uganda found that male partner involvement in ANC increased with age (Kariuki \& Seruwagi, 2016). From these studies, it would be important to investigate the same in Kenya in order to stablish whether male partner involvement in ANC increases with age.

\subsubsection{Level of Education}

In East New Britain illiteracy contributed to low male partner involvement (Holmes, et al., 2012). In Africa, a 
study in Nigeria demonstrated that male partner participation in ANC increased with the level of education. The support of an educationally informed husband improves antenatal care outcomes and can safe life especially during obstetric emergencies (Akinpelu \& Oluwaseyi, 2014). In contrast, a study in sub-Saharan found no relationship between education and male partner involvement (Ditekemena, et al., 2012). In East Africa, studies in Uganda found that, male partners who had attained secondary education were more likely to have a high male partner involvement than those with primary or no formal education (Kariuki \& Seruwagi, 2016; WHO, 2O14).

In contrast, another study conducted in Eastern Uganda found out that, education had no influence on male partner involvement in ANC (Byamugisha, et al., 2011).

In Kenya, the study in Busia on male partner involvement found that Low levels of education of male partners affected their participation in promoting skilled deliveries for their spouses, those with higher education were more involved (Nanjala \& Wamalwa, 2012).

\subsubsection{Marital Status}

Morfaw, et al. (2013) study found out that cohabiting and monogamy were associated with male involvement in antenatal care. Another study in East New Britain showed that being single and unstable marriage is associated with lack of involvement in ANC (Holmes, et al., 2012). In Africa, a study that was carried out in Ghana demonstrated that, pregnant women married legally were more than twice likely to be supported by their male partners than those in consensual union.

The level of male partner involvement was high among couples who lived together during the antenatal period than those who lived separately (Doe, 2013). Similarly, in Sub-Saharan Africa monogamous and cohabiting were associated with male partner involvement in ANC (Ditekemena, et al., 2012). Doe (2013) argued that cohabiting couples may have time to make schedules and communicate.

Although, it is not clear why polygamous male partners in Cameroon were more likely to be involved in maternal child health services, but by virtue of being married to several partners increased the chance of being invited to attend antenatal clinic many times.

In East Africa, a study in Uganda reviewed that male partner involvement was low among the single parents than those that were married and cohabiting (Kariuki1 \& Seruwagi1, 2016). In Tanzania a study showed that low male partner involvement was high in polygamous men (Kabaga, 2019). While in Kenya, monogamous and cohabiting marriages encourage male partner involvement (Morfaw, et al., 2013). Couples not cohabiting together hence lacking communication discourage male partner involvement (Nanjala \& Wamalwa, 2012)

\subsubsection{Occupation}

The study in Europe on fatherhood and health outcome demonstrates that male partners in middle working class were more involved in antenatal classes and took parental leave than low working class male partners (WHO, 2007). In East New Britain, being a commercial sex work, employment and lack of money was a hindrance to ANC involvement (Holmes, et al., 2012). The United Kingdom implemented a policy that gives fathers and partners right to have unpaid time off work to accompany expectant mothers to at least two antenatal clinic appointments (Government of UK press release, 2014). Contrast to these findings, a study in India demonstrated that, employed male partners had low involvement in ANC because they were not able to obtain leave from work to accompany their pregnant spouses (Varkey, et al., 2004).

In Africa, male partners in Nigeria argued that, financial support was their primary responsibility and therefore, reporting to work was a priority rather than accompanying their partners to the antenatal clinic (Kakaire, et al., 2011; Nkuoh, et al., 2010). In Ghana, occupation influenced male partner involvement. Civil servants were more involved with $35.2 \%$, self-employed $22.9 \%$ while unemployed were lowly involved (Doe, 2013). Similarly, in eastern Ethiopia male partner involvement in ANC services was low since they were preoccupied with work (Asefa, et al., 2014).

Although the study in Oyo state Nigeria found that occupation did not influence male partner involvement (Akinpelu \& Oluwaseyi, 2014). Morfaw, et al. (2013) found that those with financial constraints avoided ANC visits hence PMTCT recommendations not upheld. Doe (2013) argued that some male partners lack money to accompany their pregnant spouses and pay for health care cost.

In East Africa, a study in Tanzania found out that men are the bread winners therefore they had no time to accompany their spouses to ANC services (Theuring, et al., 2009). In Uganda, taxi drivers and "Bodaboda" riders had lower male partner involvement compared to farmers and contractors (Ditekemena, et al., 2012). In Busia, Kenya Nanjala and Wamalwa (2012) study found out that those with higher income and formal employment were highly involved in ANC. According to Kidero (2014) male partner involvement interferes with working schedules and men felt that time wasted at the ANC can be used to earn money for the family.

\subsubsection{Religion}

Holmes, et al. (2012) study in East Britain revealed that, religion especially Christianity play a vital role in conveying information to the community therefore it was important to target pastors with the right information concerning pregnancy and child birth so as to reach men effectively. Another study in Nicaragua Latin America revealed that religious leaders are very vital in behavior change towards involving male partners in antenatal care 
(USAID, 2014).

A study in Tanzania found that male partners who were Christian were highly involved (Kabaga, 2019). Hindu religion were highly involved in ANC than those following traditional religion (Bhatt, 2013). The study in Eastern Ethiopia found that, being a protestant increased the chance of being involved in antenatal care (Asefa, et al., 2014)

In Kenya, religion does not influence male partner involvement in utilization of skilled birth attendants (Mangeni, et al., 2013).

\subsubsection{Level of Knowledge of Male Partners}

Male partner's knowledge on maternal health needs during pregnancy and delivery, danger signs and how to intervene and birth preparedness can be enhanced through their presence during ANC visits and discussions (UNFPA, 2003; Promundo \& UNFPA 2010).

In addition, Akinpelu and Oluwaseyi (2014) stated that, male partners can positively influence $\mathrm{MCH}$ in a variety of ways, therefore, when they are informed can make sound decisions on behalf of the family for better health.

\subsubsection{Birth Plan and Emergency Preparedness}

Yargawa and Bee (2015) global study revealed that male partners' involvement in ANC enhanced ANC uptake and improved maternal health outcome. This is because male partner's knowledge on emergency preparedness increases. When male partners have inadequate knowledge on maternal health issues during pregnancy they do very little to assist (Doe, 2013) especially during emergency.

Doe (2013) further stated that, male partners' discussion about the health status of their pregnant spouses with the health provider is very important and was found to be low in Ghana. Hence, male partners had inadequate knowledge on emergency preparedness. The study in Nepal found that male partners had a low level of knowledge on birth plan and emergency preparedness (Bhatta, 2013).

In East Africa, a study in Tanzania found out that male partners exhibited low knowledge on birth plan and emergency preparedness (August, et al., 2015). In contrast, a study conducted in Uganda revealed that most of the pregnant women were accompanied by their partners and had a birth plan (Kakaire, et al., 2011). In Kenya, a study in Nairobi found out that pregnant women and their partners exhibited low knowledge on mostly all items of birth preparedness (Kipronoh, 2009). In contrast, a study conducted in Western Kenya revealed that male partners were knowledgeable on birth preparedness such as knowing the expected date of delivery (Kwambai, et al., 2013). Nanjala and Wamalwa (2012) study in Busia revealed that most of the mothers emphasized that male partners should save money for their use while accessing skilled delivery assistance.

\subsubsection{Danger Signs during Pregnancy and Delivery}

In Nicaragua Latin America, male partners were able to recognized danger signs during pregnancy (USAID, 2014). In Papua New Guinea, male partners needed to learn about danger signs during pregnancy in order to support their pregnant spouses (Holmes, et al., 2012).

In Africa, a study in South Africa found that male partners lacked knowledge on maternal health issues and services offered in ANC (Mullick, et al., 2005).

A study in Eastern Ethiopia reviewed that male partners lacked knowledge on pregnancy complications (Asefa, et al., 2014). A study in Nepal found out that male partners had a low level of knowledge on danger signs during pregnancy and delivery (Bhatta, 2013).

A study in Rwanda revealed that male partners complained of being provided with inadequate information about danger signs during pregnancy (Pafs, et al., 2015).

In East Africa, a study in Tanzania found that male partners exhibited low knowledge on danger signs during pregnancy and delivery (August, et al., 2015). In Kenya, a study by Mangeni, et al. (2013) revealed that male partners who attended antenatal clinic, their spouse utilized skilled birth attendance services during delivery meaning that they acquired knowledge on maternal health issues. Nanjala and Wamalwa (2012) study in Busia revealed that male partners had inadequate knowledge on maternal complications during pregnancy and delivery.

In contrast, another study in western Kenya found that male partners were knowledgeable on danger signs during pregnancy (Kwambai, et al., 2013)

\subsubsection{Health Education}

A study conducted in Nicaragua Latin America revealed that male partners' needed information and health education in order to get involved (USAID, 2014). In East New Britain, male partners had no knowledge on maternal issues hence they needed information in order to support their spouses during antenatal care (Holmes, et al., 2012).

A study conducted in South Africa found out that male partners were not involved in health education and received no information about ANC (Mullick, et al., 2005).

A study conducted in South Africa found out that male partners were not involved in health education and received no information about ANC (Mullick, et al., 2005). Doe (2013) stated that when male partners participate in antenatal care, they gain knowledge through health education hence are able to appreciate the 
services

In addition, Well, et al. (2015) stated that health education provided in the antenatal clinic can transform beliefs and lead to improved health behaviors. Mullany, et al. (2007) study conducted in Nepal found that, when pregnant women are educated together with their male partners they gain more knowledge which enhanced their uptake of maternal health care services. A study in Tanzania demonstrated that majority of male partners were not involved in ANC simply because they had no information about the services that were offered in the antenatal care (Theuring, et al., 2009). Onyango, et al. (2010) study in Western Kenya found that male partners were not knowledgeable on the services that were offered in reproductive health clinic. While the Mangeni, et al. (2013) study found that, male partners who attended antenatal clinic even once, their spouses were likely to deliver through a skilled birth attendance because they had acquired knowledge.

\subsubsection{Family planning (FP) information}

A study in Nicaragua Latin America reviewed that male change agents were trained to reach male partners and their pregnant spouses with family planning information (USAID, 2014) which showed that they had deficient knowledge on family planning. A study in East New Britain demonstrated that, the uptake of family planning was very low and male partners rarely used condoms and wanted to know more about family planning methods (Holmes, et al., 2012) probably because they had inadequate knowledge. In India male partners had low knowledge on family planning methods (Varkey, et al., 2004). A study in Ghana found that male partners exhibited low knowledge on family planning (Doe, 2013). I n Kenya, a study in Mavoko Sub Location Machakos County found that, it was important for male partners to increase their knowledge on the usage of condom (Kidero, 2014).

\subsubsection{HIV Testing and Counseling / PMTCT of HIV}

In the global study, it was revealed that male partners have inadequate knowledge on antenatal clinic services especially HIV testing and its importance (Morfaw, et al., 2013).

WHO (2012) male partners lack knowledge on the services offered in the antenatal clinic such as HIV testing and its importance to them. The study in South Africa found that male partners were not involved in couple counseling which theydesired (Mullick, et al., 2005).

In contrast, a study in Cameroon revealed that male partners were knowledgeable on HIV testing as ANC activity and antiretroviral drugs provided to HIV positive pregnant women prevents HIV transmission (Nkuoh, et al., 2010).

In East Africa, a study in Tanzania found that, male partners lacked knowledge on the availability of these services and their importance (Theuring, et al., 2009). In Kenya, the study in Mavoko Sub Location Machakos County found that, most of the male partners who had not participated in the ANC had not heard of PMTCT of HIV (Kidero, 2014).

While the study conducted in Busia, male partner's complaint was that they were being tested for HIV without adequate counseling (Nanjala \& Wamalwa, 2012).

In contrast, the study in Western Kenya found that some male partners exhibited knowledge on HIV test and its benefit especially mother to child prevention of HIV transmission (Kwambai et al., 2013). Kidero (2014) argues that, when male partners are included in PMTCT their HIV knowledge increases.

\subsubsection{Antenatal Checkups}

In East New Britain, male partners who accompanied their pregnant spouses in antenatal clinic were never allowed in the consultation room (Holmes, et al., 2012).

Hence did know what was being done to them. Similarly, in India male partners who accompanied their pregnant spouses to ANC did not enter the examination room but remained outside (Varkey, et al., 2004) therefore did not know what was being done to their spouses. The study in South Africa found that male partners were not involved in what was being done in the antenatal clinic (Mullick, et al., 2005). The Study in Cameroon found that male partners were knowledgeable on activities outside the examination room such as weighing, urine testing but had in adequate knowledge on antenatal examination (Nkuoh, et al., 2010).

The study in Malawi revealed that male partners were not allowed to enter the examination rooms (Kululanga, et al., 2012) hence did not know what was being done. Similarly, a study in Rwanda, found that male partners were not allowed in examination room (Pafs, et al., 2015). In East Africa, a study in Tanzania found that, male partners lacked knowledge on the availability of ANC services and their benefits to them (Theuring, et al., 2009). In contrast, the study in Western Kenya found that male partners exhibited some knowledge on antenatal checkups such as weighing, malaria parasite test, checking the baby position and blood pressure monitoring (Kwambai et al., 2013)

\section{Research Methodology}

The study adopted a descriptive cross-sectional design and provided both quantitative and qualitative data to establish the individual factors that influence male partner involvement in antenatal care in Kamenu Ward, Kiambu County. 
A simple random sampling method was employed to select a specific ward in Thika constituency and Kamenu ward was selected. The study was conducted in seven villages in Kamenu ward which constituted above $50 \%$ of the entire study area. In order to select the 7 villages, a list of the 13 villages in Kamenu ward was made and each village written in a separate piece of paper, folded, put in a bowl and shaken. Subsequently, simple random sampling method was used to select the seven villages. Systematic random sampling method was used in the villages during data collection. One household was randomly selected as a starting point and every $\mathrm{n}^{\text {th }}$ number was selected until a proportionate sample size in each village was reached. Selected participants were interviewed at their convenient time. Interviews were conducted with the help of research assistants who were selected on the basis of their level of education (that is, college level). In addition, the study had a Focused Group Discussions (FGDs) which comprised of seven male partners selected from the seven villages. The FGD was held at Juakali multipurpose hall and data was collected using FGD guide. The study also adopted quantitative approaches of data collection and analysis. The independent variables in this study included; demographic factors and knowledge.

The dependent variable was the male partner involvement in antenatal care. The target Population was all the males within the age of 18 and 90 years. The study Population were the 384 male partners sampled.

The study included the male partners in the age group of 18 - 90 years, whose spouse was either pregnant or had a child aged 3 years or less. In addition, the male partner participants must have been residents of Kamenu Ward and those who consented.

Male partners excluded in the study were those not within the age group of 18-90 years or with children older than 3 years or spouse not pregnant were not considered. Moreover, male partners who were not residents of Kamenu Ward and their spouses were pregnant were not considered for inclusion.

Data collection procedure involved a self-administered questionnaire. The researcher pre-tested the study instrument for reliability and validity. After the pre-test, the instrument was then fit for the actual data collection.

\subsection{Data Analysis and Presentation}

The data was analyzed using Microsoft excel spread sheet and SPSS Volume 23. Data analysis was done using descriptive and inferential statistics to determine significant association between the independent and dependent variables. Inferential statistics was computed from the quantitative data obtained to derive on the sum $\mathrm{P}$. Values. The significant level was set at 0.05 . The results were presented in tables, frequencies, pie charts, percentages, mean and standard deviation.

\section{RESEARCH FINDINGS}

\subsection{Male Partner's Factors}

\subsubsection{Age, Marital Status, Level of Education and Occupation}

Results presented in Table 4.1 indicate that majority 116(30.4\%) were aged 18-23, followed by 96(25.6\%) aged 24-29 years, while 71(18.6\%) were aged 30-35 years and only 19(5.0\%) were 48 years and above. Regarding marital status, majority of the respondents $283(74.3 \%)$ were married in a monogamous family, $69(18.1 \%)$ were married in a polygamous family, 21(5.5\%) were single parents, while $4(1.0 \%)$ of respondents were separated and $4(1.0 \%)$ completely divorced. In addition, findings in Table 4.1 show that $37.5 \%$ had pursued a college level of education, $31.5 \%$ had completed secondary school education, $20.2 \%$ had primary education and $10.2 \%$ with university degrees and only $0.5 \%$ had not attended school whatsoever. With regard to occupation, majority $133(36 \%)$ were business men, $78(21.1 \%)$ teachers, $47(12.7 \%)$ subordinate staffs, 33(8.9\%) managers, $23(6.2 \%)$ grocery venders, $16(4.3 \%)$ nurses, $15(4.1 \%)$ doctors and $11(3 \%)$ accountants. 


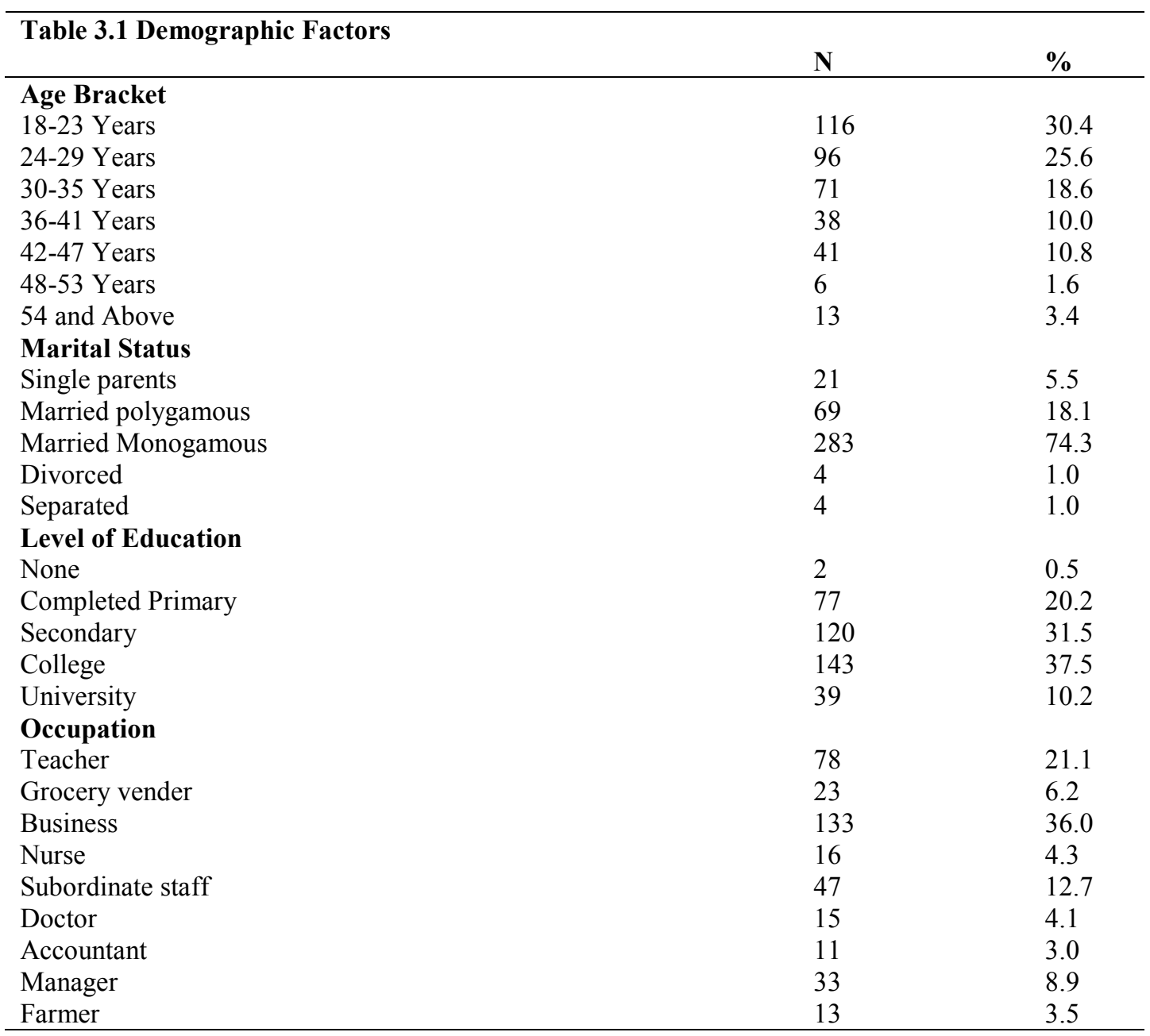

Notes: $\mathbf{N}=\mathbf{3 8 1}$

Qualitative analysis of respondents' demographic revealed quite important information in relation to male partner participation to antenatal care. For example, one of the respondents had this to say:

"Male partners who are young in age do not like being seen with their pregnant spouses while those aged and are married to younger women were ashamed of being seen with them" (42 year old male partner). However, one respondent had to say this:

"Male partners with good occupation and a high level of income are more likely to be involved in antenatal care than those with a low level of income or don't have good occupation.

This is because male partners with good occupation can afford all the expenses at health facilities for their spouses."

\subsubsection{Respondents' Religion}

Results of respondents' religion illustrated in the figure 4.1 revealed that majority $(86.5 \%)$ of the respondents were Christians, $12.6 \%$ Muslims, $4.0 \%$ Hindus and the rest were $(0.8 \%)$ were pagans. 


\subsubsection{Respondent Christians Denomination}

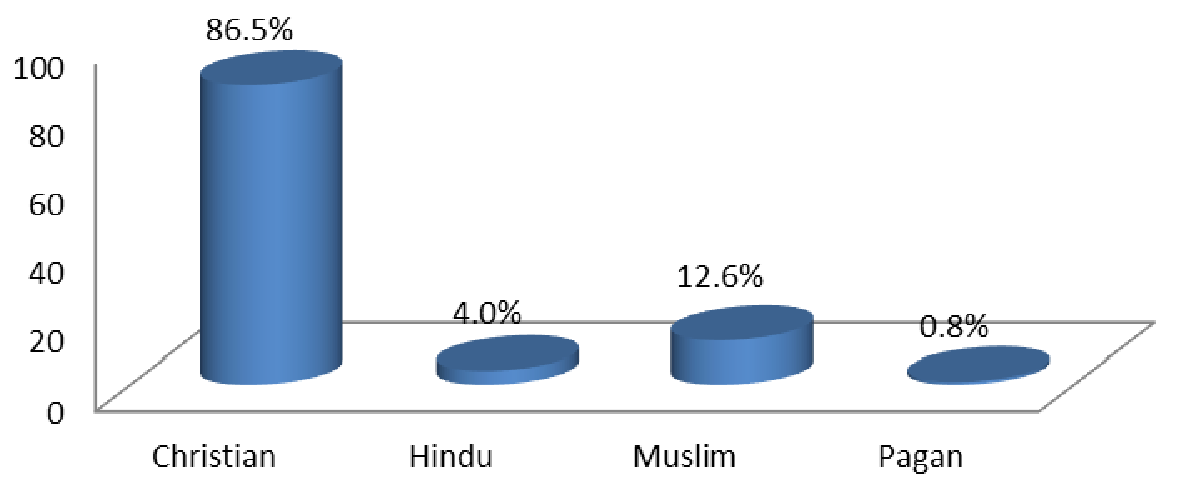

\section{Figure 3.1 Religion of the Respondents}

Results on various denominations of respondent Christians revealed that majority (54.3\%) were Protestants, 40.5\% were Catholics and 5.2\% Adventists as illustrated in Figure 4.2.

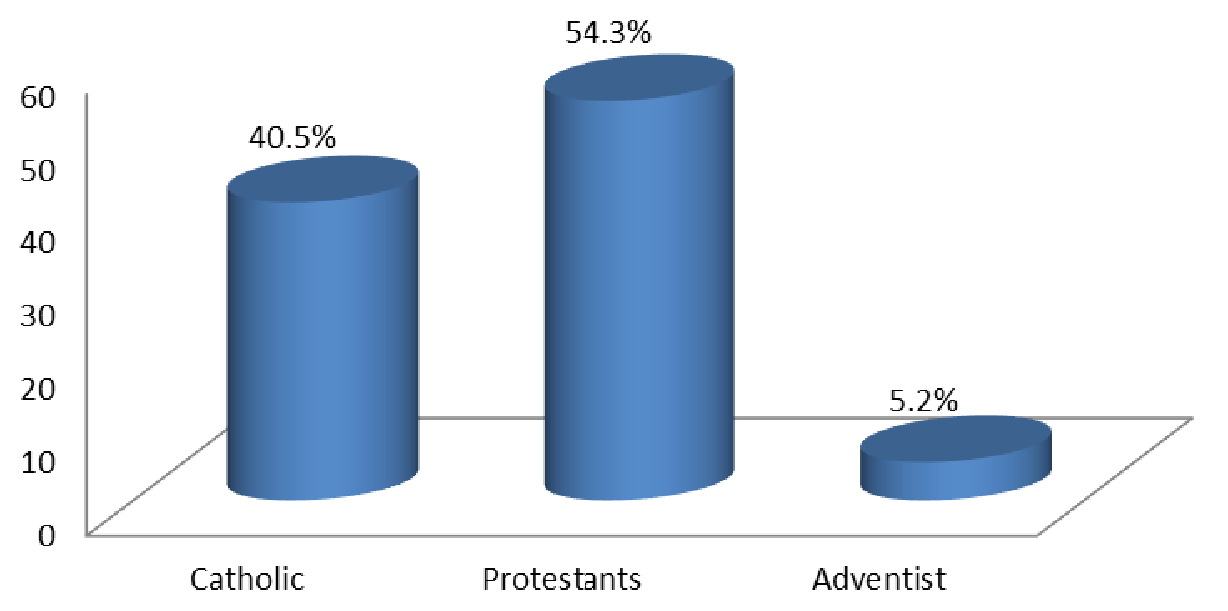

Figure 3. 2 Respondents Christian denomination

Study findings further revealed that male partners' religion may play a vital role towards their spouses' decision to seek antenatal clinic services. In this regard one retorted that:

"Muslim women who initiated to seek antenatal care mostly sought approval from their male partners to visit antennal clinics" (A 44 year old respondent).

Another Muslim respondent reported that:

"Your wife is just like your child...she (wife) should take permission from her husband before doing anything....even before going to the clinic to seek care...this is in line with our religion (Islam) and our tradition and culture" (A 43 year old respondent).

\subsubsection{Employment Status}

Results of the respondents' employment status showed that $52.2 \%$ had formal employment, and $46.8 \%$ were self-employed. However, about $1.0 \%$ did not respond to this question as shown in Figure 4.3. 


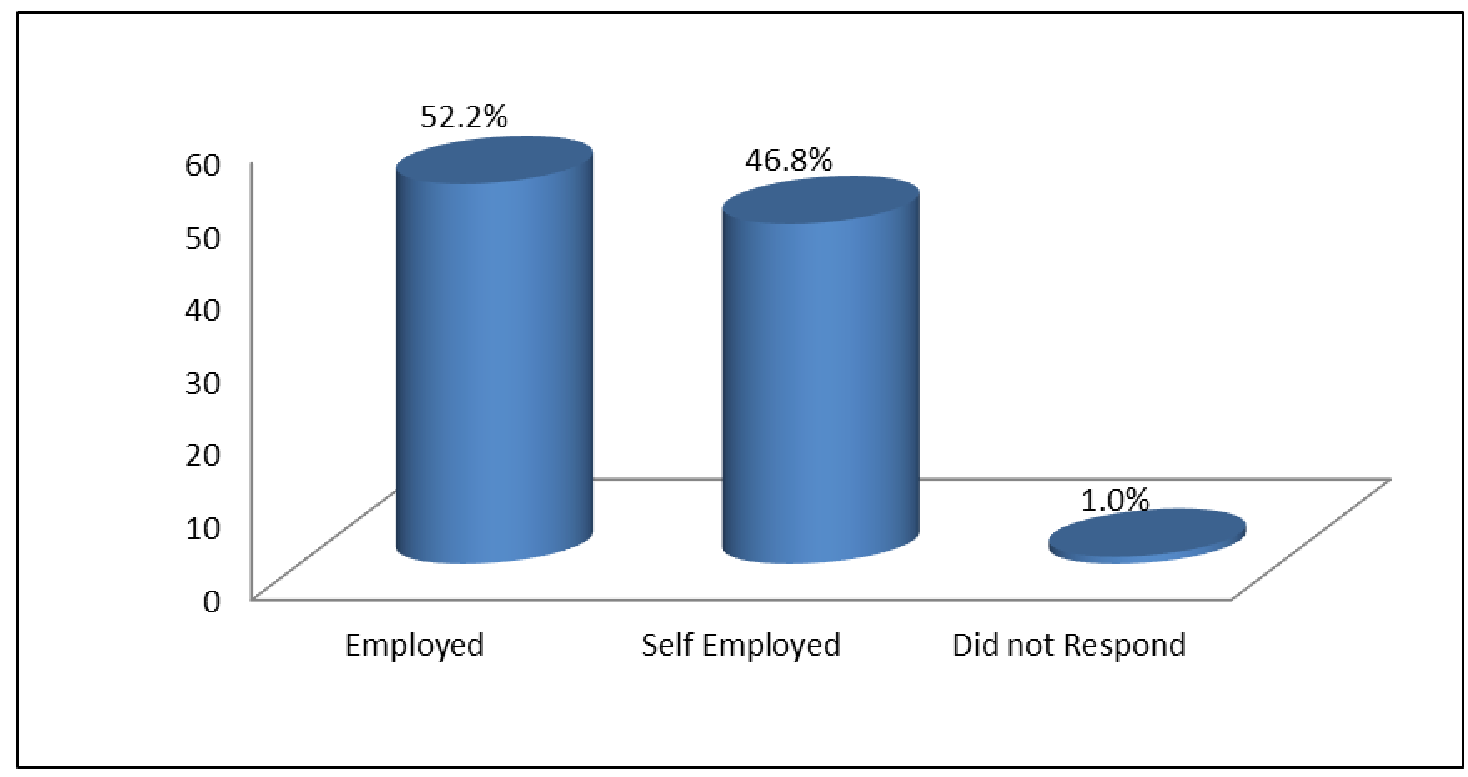

Figure 3. 1 Employment Status

3.1.5 Knowledge of Male Partners on Maternal Health Issues and Antenatal Services

Results presented in Table 3.3 indicate that majority 144(38.4\%) of respondents' knowledge on birth plan and emergency preparedness was good and 127(33.9\%) was fair. Regarding danger signs during pregnancy and delivery, $185(59.6 \%)$ said it was good and $122(32.8 \%)$ said it was fair. In terms of HIV counseling services and testing/PMTCT, majority 203(54.1\%) reported that it was very good and $24.3(24.8 \%)$ said it was good.

Table 3. 1 Rating on Knowledge of Male Partners on Maternal Health Issues and Antenatal Services

\begin{tabular}{llllllll}
\hline Statements & $\mathbf{1}$ & $\mathbf{2}$ & $\mathbf{3}$ & $\mathbf{4}$ & $\mathbf{5}$ & Mean & SD \\
\hline Birth plan and emergency & 15 & 42 & 127 & 144 & 47 & & \\
preparedness & $(4.0 \%)$ & $(11.2 \%)$ & $(33.9 \%)$ & $(38.4 \%)$ & $(12.5 \%)$ & 3.44 & 1.03 \\
Danger sings during pregnancy & 20 & 8 & 122 & 185 & 37 & & \\
and delivery & $(5.4 \%)$ & $(2.2 \%)$ & $(32.8 \%)$ & $(49.7 \%)$ & $(9.9 \%)$ & 3.57 & 1.35 \\
HIV counseling and & 2 & 14 & 63 & 93 & 203 & & \\
testing/PMTCT & $(0.5 \%)$ & $(3.7 \%)$ & $(16.8 \%)$ & $(24.8)$ & $(54.1 \%)$ & 4.28 & 0.86 \\
Family planning & 7 & 16 & 67 & 190 & 95 & & \\
& $(1.9 \%)$ & $(4.3 \%)$ & $(17.9 \%)$ & $(50.7 \%)$ & $(25.3 \%)$ & 3.93 & 1.02 \\
Antennal checkups & 25 & 25 & 175 & 122 & 28 & & \\
& $(6.7 \%)$ & $(6.7 \%)$ & $(46.7 \%)$ & $(32.5 \%)$ & $(7.5 \%)$ & 3.27 & 1.36 \\
\hline
\end{tabular}

Notes: 1 = Very poor, 2 = Poor, $3=$ Fair, 4 = Good, $5=$ Very Good

On family planning services, $185(76.0 \%)$ reported that it was good while only $67(17.9 \%)$ saying it was fair. Interesting 175(46.7\%) said that antenatal checkups knowledge was fair and 122(32.5\%) saying it was good with the lowest mean rating of (3.27). In general, results in Table 4.2 demonstrated that the level of knowledge by male partners on maternal health issues was good and on antenatal checkups was fair. One respondent reported that:

"In as much as we have been trying to accompany our spouse most of the time we are left outside the examination room hence not aware of the services that are offered inside the room."

Hypothesis Testing on Relationship between Level of Knowledge of Male Partners and their Involvement in ANC.

As contemplated in objective four, the study hypothesized that level of knowledge of male partners have no influence on male partner involvement in antenatal care in Kamenu sub location Kiambu County. The Pearson's chi-square test was used to establish if there is a relationship between the two categorical variables. The ChiSquare test result is presented in Table 3.3 below.

Table 3.3: Chi-Square Test Results for Relationship between Level of Knowledge of Male Partners and their Involvement in ANC

\begin{tabular}{llrc}
\hline & \multicolumn{1}{c}{ Value } & df & Asymp. Sig. (2-sided) \\
Pearson Chi-Square & $16.15^{\mathrm{a}}$ & 4 & 0.003 \\
Likelihood Ratio & 21.55 & 4 & 0.000 \\
N of Valid Cases & 375 & & \\
\hline
\end{tabular}

As shown in Table 3.3, the Pearson Chi-Square value was 16.15 and $p$ value of 0.003 which reveals that that there was statistically significant association between level of knowledge of male partners and their 
Involvement in ANC. This therefore means that the hypothesis $\mathrm{H}_{0} 4$ that there is no significant relationship between level of knowledge of male partners and their involvement in ANC is rejected. This is because the $p$ value of 0.003 was far within the 0.05 alpha value for the result to have statistical significance.

\section{Discussion}

\subsection{Male Partner Factors and Involvement in ANC}

\subsubsection{Age}

In this study majority $116(30.4 \%)$ of the participants were aged between 18-23 years, followed by $96(25.6 \%)$ aged between 24-29 years. This could be attributed to the fact that this is an age group with a high population (County Government of Kiambu, 2015) and which is sexually active. Additionally, majority of the respondents $283(74.3 \%)$ were married in a monogamous family. This could be due to the fact that $86.5 \%$ of the respondents were Christians who encourages monogamous marriage. Majority $86.5 \%$ of the respondents were Christians, $12.6 \%$ Muslims and $4.0 \%$ Hindus and the rest were $(0.8 \%)$ were pagans.

\subsubsection{Religion}

Religion as a male partner factor was important for this study as it was reported for instance that decision making powers of male partners were said to be derived from religious obligations.

\subsubsection{Education level}

Majority of the respondents $143(37.5 \%)$ had attained college level of education and 120(31.5\%) Secondary Level. Pearson correlation results at 5\% significance level revealed a strong significant positive relationship $(r=$ $0.561, p<.001)$ indicating that male partner factors plays a key positive role towards male partner involvement in ANC.

The study findings are consistent with a study in Uganda that found male partners who had attained secondary education were more likely to have a high male partner involvement than those with primary or no formal education (WHO, 2O14: Kariuki1 \& Seruwagi1, 2016). Similarly, Nanjala and Wamalwa (2012) contended that it can be argued that male partners with some basic level of education better understand the complications associated with unskilled delivery.

\subsubsection{Knowledge}

Majority of male partners 144(38.4\%) indicated that their knowledge on birth plan and emergency preparedness was good and $127(33.9 \%)$ said it was fair. These results concur with a study conducted in Western Kenya that found male partners were knowledgeable on birth preparedness such as knowing the expected date of delivery (Kwambai, et al., 2013). In contrast, Kipronoh (2009) found that pregnant women and their partners exhibited low knowledge on mostly all items of birth preparedness.

Regarding danger signs during pregnancy and delivery, $185(59.6 \%)$ said it was good and $122(32.8 \%)$ said it was fair. Male partners in this study were knowledgeable on danger signs most likely because the antenatal booklet that is issued to the antenatal mothers has this information. Similarly, a study in western Kenya found that male partners were knowledgeable on danger signs during pregnancy (Kwambai, et al., 2013). In contrast a study in Tanzania found that male partners exhibited low knowledge on danger signs during pregnancy and delivery (August, et al., 2015). According to Mangeni, et al. (2013) study in Nairobi County, if male partners were found to attend antenatal clinic, their spouses utilized skilled birth attendance services during delivery because they acquired knowledge on maternal health issues. In addition 175(46.7\%) said that antenatal checkups knowledge was fair and $122(32.5 \%)$ reported that it was good. These findings are in line with the study in Western Kenya that found male partners exhibited some knowledge on antenatal checkups (Kwambai et al., 2013).

This is in contrast with the findings of a study in Tanzania that found out that male partners lacked knowledge on the availability of ANC services (Theuring, et al., 2009). In terms of HIV counseling services and testing/PMTCT, majority 203(54.1\%) reported that it was very good and $24.3(24.8 \%)$ said it was good. This result was in accordance with the findings of a study in Western Kenya that found out that some male partners exhibited knowledge on HIV test (Kwambai et al., 2013). Kidero (2014) have argued that, when male partners are included in PMTCT, their HIV knowledge increases. In contrast, the study in Mavoko Sub Location Machakos County found that, most of the male partners who had not participated in the ANC had not heard of PMTCT of HIV (Kidero, 2014). On family planning services, $185(76.0 \%)$ reported that it was good while only $67(17.9 \%)$ reported it was fair.

This implied that male partners were knowledgeable on family planning services. This is in contrast with the findings of a study in Ghana that found out that male partners exhibited low knowledge on family planning (Doe, 2013).

In Kenya, the study in Mavoko Sub Location Machakos County found that, it was important for male partners to increase their knowledge on the usage of condom (Kidero, 2014). 


\section{Conclusions}

On the basis of the study findings, it was concluded that male partner factors such as knowledge of ANC, nature of employment, age, marital status, religion and level of education influences male partner involvement in ANC positively. If the knowledge is enhanced through health education and other individual factors be addressed, more male partner involvement would be achieved.

\section{REFERENCES}

Akinpelu, O. \& Oluwaseyi, O. (2014). Attitude and Practice of Males towards Antenatal Care in Saki West Local Government Area of Oyo State, Nigeria. Advances in Life Science and Technology, 22, 56-62.

Asefa, F., Geleto, A., \& Dessie, Y. (2014). Male partner's involvement in maternal ANC care: The view of women attending ANC in Hararipublic Health Institutions, Eastern Ethiopia. Science Journal of Public Health, 2(3), 182-188.

August, F., Pembe, A., Mupembeni, R., Axemo, P., \& Darj, E. (2015). Men's knowledge of Obstetric Danger Signs, Birth Preparedness and Complications redness in Tanzania. Plos One, 10(5), 1-12.

Bhatta, D. (2013). Involvement of males in antenatal care, birth preparedness, exclusive breastfeeding and immunization for children in Kathmandu, Nepal. BMC pregnancy and childbirth. Journal of Health, Medicine and Nursing, 27, 14-23.

Ditekemena, J., Koole, O., Engmann, C., Malend, R., Tshefu, A., Ryder,R., \& Colebunder, R. (2012). Determinants of male involvement in maternal and child health services in sub-Saharan Africa: a review. Reproductive health journal, 9(12), 234-48.

Doe, R. (2013). Male partner involvement in maternity care in Ablekuma south district, Accra, Ghana. Government of United Kingdom. (2014) Press release: new right for fathers and partners to attend antenatal appointments.

Holmes, W., wambo, G., Gabong, R,. Kavang, E., Luana, S., Sawa, A., SuPsuP, H., reeders, J., Assidy, C., \& Natoli, J. (2012). 'Because it is a joyful thing to carry a baby': Involving men in reproductive health, maternal and newborn health in East New Britain Papua in New Guinea.

Kabanga, E., Chibwae, A., Basinda, N. \& Domenica Morona, D (2019). Prevalence of male partners involvement in antenatal care visits - in Kyela district, MbeyaBMC Pregnancy and Childbirth,321 (2019)

Kakaire, O., Kaye D., \& Osinde M. (2011). Male involvement in birth preparedness and complication readiness for emergency obstetric referrals in rural Uganda. Reproductive Health Journal, 8(12), 1-7.

Kariuki, F. Kinuthia \& Seruwagi K. Gloria. (2017). Determinants of Male Partner Involvement in Antenatal Care in Wakiso District, Uganda. British Journal of Medicine \& Medical Research 18(7): 20-43.

Kaye, D., Kakaire, O., Nakimuli, A., Osinde, M., Mbalinda, S., \& Kakande, N. (2014). Male involvement during pregnancy and child birth: men's perceptions, practices and experiences during the care for women in developed child birth complications in Mulango hospital, Uganda.

Kidero, E. (2014). Exploring male attitudes on involvement in antenatal care: the case of prevention of motherto-child transmission of HIV in Athi river sub-location of Mavoko constituency, Machakos County.

Kipronoh, M. (2009). Factors influencing the quality of antenatal care in public maternal and child health facilities in Nairobi province, Kenya.

Kwambai, K. et al., (2013). Perspectives of men on antenatal and delivery care service utilization in rural western Kenya: a qualitative study.

Kululanga, L. Sundby, J., Malata, A., \& Chirwa, E. (2011). Striving to promote male involvement in maternal health care in rural and urban settings in Malawi - a qualitative study. African Journal of Reproductive Health, $16(1): 149-160$.

Mangeni, J., Mwangi, A., Mbugua, S., \& Mukthar, V. (2013). Male Involvement in Maternal Health Care as a Determinant of Utilization of Skilled Birth Attendants in Kenya. DHS Working Papers, Published by USAID.

Morfaw, F. Mbuagbaw,L. Thabane, L., Rodrigues, C., Wunderlich, A., Nana, P. \& Kunda, J. (2013). Male involvement in prevention programs of mother to child prevention of HIV: a systematic review to identify barriers and facilitators. Biomed central Journal.

Mullany, B., Becker, S. \& Hindin M. (2007). Impact of husbands' participation in antenatal health education services on maternal practices in urban Nepal: results from a randomized controlled trial, John Hopkins

Mullick, S., Kunene, B. \& Wanjiru, M. (2005). Involving men in maternity care: Health service delivery issues, Population Council.

Nanjala M, \& Wamalwa D. (2012). Determinants of male partner involvement in promoting deliveries by skilled attendants in Busia, Kenya. Global Journal of Health Science, 4(2): 60-67.

Nkuoh, G. (2010). Barriers to men's participation in antenatal and prevention of mother-to-child HIV transmission care in Cameroon. Africa. J Midwifery Women's Health, 55(4):363-9.

Onyango, A., Owoko, S \& Oguttu, M., (2010). Factors that influence male involvement in reproductive health in 
Western Kenya: A qualitative study. African journal, 14(4), 32-42.

Pafs, J., Musa, A., Finnema,P., Allvin, M., Rulisa, S., \& Essen, B. (2015). They would never receive you without a husband: paradoxical barrier to antenatal care scale up in Rwanda.

Promundo, UNFPA \& Engage men. (2010). Engaging Men and Boys in Gender Equality and Health: A Global Tool kit for Action.

Singh, D., May, L., \& Jaya E. (2014). The involvement of men in maternal health care: cross-sectional, pilot case studies from Maligita and Kibibi, Uganda. Reproductive Health Journal,

Theuring, S. et al., (2009). Male Involvement in PMTCT Services in Mbeya Region Tanzania. AIDS and Behavior Journal.

Thomson, L., Mavhu, W., Makungu, C., Nahar, Q., Khan, R., Davis, J., Hamdani, S., Stillo, E, \& Luchters, S. (2015). Men Matter: Engaging men for better MNCH outcomes. Plan Canada. Toronto.

Varkey, L. (2004). Involving Men in Maternity Care in India. Frontiers in Reproductive Health Program Population Council. New Delhi, India Maternal Health Task Force. 2015.

World Health Organization. (2012). Male Involvement in the Prevention of Mother-to Child Transmission of HIV.

Wells, M., Mitra, D., \& Flanagan, K. (2015). State of Australia's fathers. Men care campaign.

Yargawa, J., \& Bee, L. (2015) Male involvement and maternal health outcomes: Systematic review and metaanalysis.

\section{ACKNOWLEDGEMENT}

I sincerely appreciate Dr Jane Karonjo Dean nursing Mount Kenya University and Dr Rosemary Okova Senior Lecturer Mount Kenya University for their indispensable guidance throughout this study.

My gratitude goes to all Mount Kenya University lectures in the School of Nursing and research Department. I am indebted to my husband and the children for support they offered to me during this period of time. Not leaving behind the research assistants, my colleagues and friends for whichever way they supported me.

I acknowledge Kiambu County leadership, Kamenu sub location community for their cooperation and contribution during the study. The participants are highly appreciated for offering their time to provide valuable information that made this study successful. 